16 | InterAção

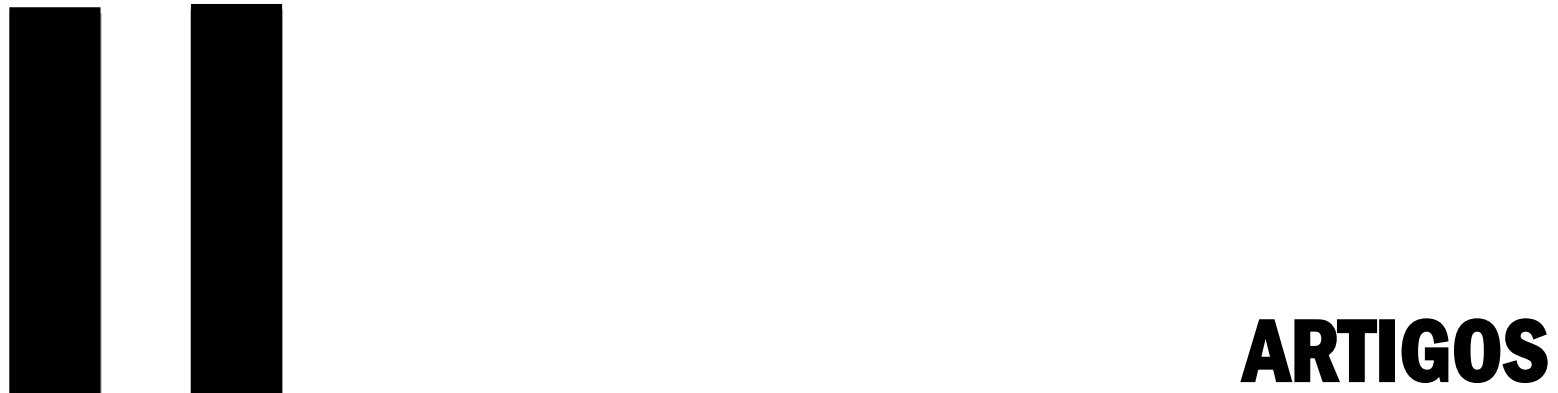


17 InterAção

\title{
A GUERRA DO IRAQUE EM PERSPECTIVA: UM BALANÇO DA POLÍTICA EXTERNA NEOCONSERVADORA E $O$ ÔNUS DA GUERRA
}

\author{
Gustavo Fornari Dall'Agnol ${ }^{1}$
}

Bruno Hendler ${ }^{2}$

Devo estudar política e guerra para que meus filhos possam ter a liberdade de estudar matemática e filosofia, geografia, história natural, arquitetura naval, navegação, comércio e agricultura, a fim de que deem a seus filhos o direito de estudarem pintura, poesia, música, arquitetura, estatuária, tapeçaria e porcelana.

John Adams ${ }^{3}$

A árvore da liberdade deve ser renovada de tempos em tempos com o sangue de patriotas e tiranos. Isso é a forma natural.

Thomas Jefferson ${ }^{4}$

\footnotetext{
${ }^{1}$ Bacharel em Relações Internacionais pela Universidade Federal de Santa Catarina (UFSC) e Mestre em Economia Política Internacional pela Universidade Federal do Rio de Janeiro (UFRJ). Email: gustfd@gmail.com

${ }^{2}$ Mestre em Relações Internacionais pela Universidade de Brasília (UnB) e doutorando em Economia Política Internacional pela Universidade Federal do Rio de Janeiro (UFRJ). Bolsista CAPES. Email: bruno_hendler@hotmail.com

${ }^{3}$ John Adams (1735-1826) foi o segundo presidente dos Estados Unidos (1797-1801).

${ }^{4}$ Thomas Jefferson (1743-1826) foi um dos principais autores da Declaração da Independência (1776) e 0 terceiro presidente dos Estados Unidos (1801-1809).
} 


\section{Resumo}

O presente trabalho tem como objetivos: a) compreender o processo de ascensão do movimento neoconservador norte-americano e sua estratégia global de forma a compreender a Guerra do Iraque (2003-2011) a partir do contexto da Guerra ao Terror, protagonizada pela administração George W. Bush; e b) realizar um balanço do ônus da Guerra do Iraque para a economia dos Estados Unidos. Para tanto, o trabalho está dividido em três partes. A primeira debate a edificação do arquétipo do pensamento conservador na sociedade norte-americana. A segunda parte trata da Guerra do Iraque em si. A ascensão dos neoconservadores ao governo dos Estados Unidos e os atentados de 11/09 foram os eventos que significaram a possibilidade de colocar em prática o projeto de domínio do Oriente Médio e controle do petróleo no Golfo Pérsico, cumprindo vários objetivos necessários para a expansão do poder norte-americano. Entre esses objetivos encontram-se: a contenção da China e da Rússia no território asiático; o controle de recursos estratégicos como o petróleo; o posicionamento de bases militares em territórios chave; a intervenção em regimes contrários aos interesses norte-americano em todo o Oriente Médio; e o auxílio a aliados chave como Israel e Arábia Saudita no cenário geopolítico asiático. Por fim, faz-se um breve balanço das consequências do "atoleiro iraquiano" para a economia e sociedade dos EUA.

Palavras-chave: Estados Unidos; Iraque; política externa; neoconservadores; geopolítica.

\section{Abstract}

The presente paper aims at: a) understanding the rising process of the neoconservative movement in the United States and it's global strategy in order to understand the Iraq war (2003-2010) through the War on Terror context, protagonized by the George W. Bush administration and; b) Analyze the onus of the Iraq war to the United States economy. The pape is divided in three parts. The first debates the edification of the conservative ideology archetype in north-american society. The second part is dedicated to understanding the Iraq War. The rise of the neconservatives towards government and the 9/11 terrorist attacks were the events which meant the possibility to put in practice the Middle East dominion strategy and the oil supply control in the Persian Gulf, thus, fulfilling many of the necessary goals towards the United States power expansion. These goals include: the containment of China and Russia in Asia; the control of strategic resources like oil; the expansion of military bases in key territories; the intervention in regimes contrary to United States interests in Middle East; and maintaining key allies like Israel and Saudi Arabia in the asian geopolitical contexto. Finally, the paper briefly analysis the consequences of the Iraq occupation for the United States society and economy.

Keywords: United States; Iraq; foreign policy; neoconservatives; geopolitcs. 


\section{INTRODUÇÃO}

A Guerra do Iraque vista a guisa do tempo presente foi onerosa em muitos sentidos. Quais foram os interesses que motivaram o governo norte-americano a praticar tal ocupação? Qual foi o legado dessa guerra para a sociedade norteamericana? Para responder tais questões, o presente trabalho tem como objetivos: a) compreender as bases e a ascensão do movimento neoconservador norte-americano e sua estratégia global de forma a examinar a Guerra do Iraque (2003-2011) a partir do contexto da Guerra ao Terror, protagonizada pela administração George W. Bush; e b) realizar um balanço do ônus da Guerra do Iraque para a economia a política e a sociedade dos Estados Unidos. Para tanto, o trabalho está dividido em três partes. A primeira debate a edificação do pensamento e da práxis neoconservadora nos Estados Unidos, enfatizando o papel central que o controle e a ocupação do Iraque deveriam exercer na reformulação do sistema internacional com a reafirmação dos EUA como única superpotência. A segunda parte trata da Guerra do Iraque em si. A ascensão dos neoconservadores ao governo dos Estados Unidos e os atentados de 11/09 foram os eventos que significaram a possibilidade de colocar em prática o projeto de domínio do Oriente Médio e controle do petróleo no golfo pérsico, cumprindo vários objetivos necessários para a expansão do poder norte-americano. Entre esses objetivos encontram-se: a contenção da China e da Rússia no território asiático; o controle de recursos estratégicos como o petróleo; o posicionamento de bases militares em territórios chave; a intervenção em regimes contrários aos interesses norte-americano em todo o Oriente Médio; e o auxílio a aliados chave como Israel e Arábia Saudita no cenário geopolítico asiático. Por fim, faz-se um breve balanço das consequências da Guerra do Iraque para a economia

norte-americana e o cenário geopolítico atual do Oriente Médio. Do nosso ponto de 
20 InterAção

vista esse trabalho justifica-se pela ainda complicada relação da política externa norte-americana e a situação do Oriente Médio, sendo que, a primeira está amplamente desacreditada como líder moral e com capacidade real de resolução de conflitos e a segunda sofre mergulhada em guerras e sublevações.

\section{COMUNIDADES COLONIAIS, FORMAÇÃO DE VALORES E OS PARÂMETROS DEFINIDORES DA POLÍTICA EXTERNA DOS ESTADOS UNIDOS}

A guerra é uma atividade legítima para os norte-americanos e está enraizada em sua história. A questão não é "se devemos lutar?", mas "que tipo de guerra devemos lutar?". E é esta questão que definiu (e continua a definir) os parâmetros definidores da política externa dos EUA. Para Stephen P. Rosen (2009), duas culturas bem definidas de colonos deixaram sua marca na formação dos valores norteamericanos e, de certa forma, seus princípios permanecem até hoje: os escoceses e irlandeses (Scots-Irish) e os puritanos. Uma breve análise de suas características pode ser elucidativa para se compreender as raízes do pensamento neoconservador (HENDLER, 2015).

Os Scots-Irish se fixaram majoritariamente nas colônias do sul e vinham de um clima de guerra característico das ilhas britânicas, onde disputas por terra, gado e religião eram, certa forma, naturais - e isso se refletiu nos conflitos com os povos indígenas nos Estados Unidos (KARNAL, 2007, p. 71-74). Do ponto de vista desta cultura os líderes deveriam ser fortes, enérgicos e pragmáticos, sempre de prontidão para revidar quaisquer ameaças aos interesses materiais de sua comunidade. 
21 InterAção

Já para os puritanos, fixados majoritariamente nas colônias no norte, a violência também era comum. No entanto, para esta cultura, a violência deveria ser previamente autorizada pela comunidade e pela norma social vigente. Dessa forma, a guerra deveria ser justa, com vistas a uma causa maior, como a defesa contra os indígenas ou os ingleses, a caça às práticas religiosas heréticas, a difusão de valores religiosos e/ou a concretização de um destino manifesto.

Em 1890, o sociólogo norte-americano, Frederik Jackson Turner, afirmava que "por cerca de três séculos o fator preponderante na vida norte-americana tem sido a expansão". Tal expansão é melhor demonstrada pela figura abaixo:

Figura 1: Expansão territorial norte-americana (1803-1917)

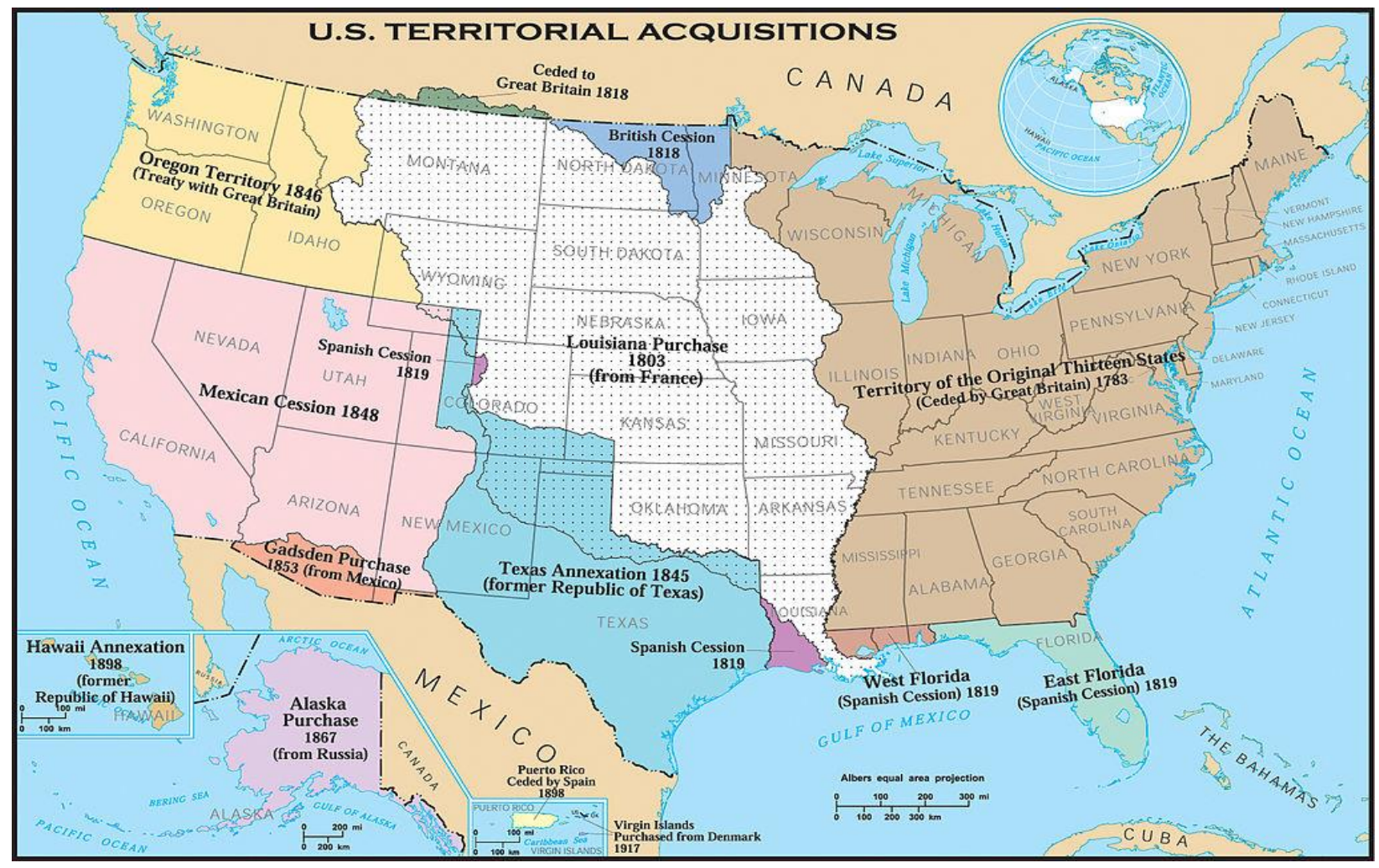

Fonte: THE TIMES. Atlas da História do Mundo. Empresa Folha da Manhã S.A., São Paulo, 1995. 
22 InterAção

A afirmação de Turner é corroborada por José Luís Fiori (2008, p. 35) que pondera: “a projeção internacional do poder americano não é um fenômeno novo: começou pouco depois da independência dos Estados Unidos e se prolongou, de forma contínua, pelos séculos XIX e XX". A postura dos EUA em relação ao exterior passou a ocorrer através de diversos conflitos, em uma mistura de interesses pragmáticos e valores morais. Esses conflitos adquiriram várias roupagens durante a história dos Estados Unidos.

A partir de 1898, com a guerra hispano-americana, a manifestação do conflito entre as duas culturas supracitadas se deu no debate entre isolacionistas e intervencionistas. Tal debate é bem exemplificado pela manifestação concreta no século XX entre os dois líderes Woodrow Wilson e Theodore Roosevelt.

A vertente dos governos de Woodrow Wilson (1902-1910) pode ser percebida como uma expressão do puritanismo, já que a defesa dos valores democráticos dos Estados Unidos deveria valer para o resto do mundo, pois há uma crença na excepcionalidade do país. Dessa forma, tal perspectiva pode ser qualificada como dogmática (idealista) Já a vertente dos governos de Roosevelt (1933-1945) é também uma expressão da cultura Scot-Irish e da defesa do interesse pragmático, onde se justifica a intervenção com base na defesa do interesse nacional. Pode-se afirmar que tal concepção é empírica (realista). A postura de tais governos diante do cenário internacional é uma expressão da conduta mais geral dos Estados Unidos que adquire mais uma vez doses de idealismo e realismo.

O embate entre idealistas e realistas voltou à tona no turbilhão social que atingiu os Estados Unidos em 1968. Os movimentos por direitos civis que se construíram e se fortaleceram ao longo dos governos de John F. Kennedy (1960-1963) e Lyndon B. Johnson (1963-1968) polarizaram o país. No plano interno os 
23 InterAção

movimentos por direitos civis deram origem à chamada Nova Esquerda identificada pelos movimentos de contracultura, liberdade social e crítica às ações dos governos democratas no plano internacional. A guerra do Vietnã (1965 a 1974) foi um verdadeiro fracasso do ponto de vista civil, já que deixou 57 mil soldados americanos mortos e 300 mil feridos. Com um breve hiato, de 1968 a 1974, em que os EUA estavam sob comando de Richard Nixon, as décadas de 1960 e 1970 foram de liderança democrata. Se por um lado os movimentos sociais visavam maior liberdade e democracia, os governos democratas se deparavam com a estrutura do sistema internacional. A guerra fria e a contenção da União Soviética, além da crescente perda de competitividade frente à Alemanha e ao Japão ressaltavam o expansionismo norte-americano. No plano doméstico os governos democratas reprimiam duramente os movimentos sociais para manter "a casa em ordem". Essas tensões levaram a uma contraofensiva conservadora manifestada nas eleições de 1980 (KARNAL, 2007, p. 235).

Em 1980, na reta final da campanha, o embate se travou, entre o então presidente Jimmy Carter e o ex-governador da Califórnia Ronald Reagan. A discórdia ficou evidenciada em dois pontos principais: A crise econômica e a suposta crise na política externa expressa pelo avanço da URSS, que do ponto de vista dos principais quadros sob o comando de Reagan eram uma expressão do fracasso das “décadas democratas" em conter o “inimigo" externo e interno (KARNAL, 2007, p. 235-255)5 . O inimigo interno era o excessivo tamanho do Estado e dos gastos sociais,

\footnotetext{
${ }^{5}$ No discurso de 03 de Novembro de 1980, na véspera da eleição, Ronald Reagan afirmou "Não me compreenda mal, nenhum homem razoável que vê o mundo como ele está, que vê a deterioração das nossas relações com os nossos aliados, que vê o enfraquecimento da nossa economia, o crescente aumento do poder soviético e os sofrimentos do nosso passado recente pode subestimar as dificuldades diante de nós". No entanto, se os eleitores apostassem nele o mundo iria ver que "os Estados Unidos ainda estão unidos, fortes e lutando pelo sonho de paz e liberdade. Os Estados Unidos ainda está disposto a ficar do lado daqueles que são perseguidos e solitários". Tradução Própria. Disponível em: http://www.reaganlibrary.gov/major-speeches-index. Acesso em: Novembro, 2015.
} 
$24 \mid$ InterAção

que para os conservadores enfraquecia os Estados Unidos frente ao cenário internacional e impedia a prevalência da "livre iniciativa" e da "valorização do mérito". Entre 1981 a 1987, principalmente depois de 1983 com o plano "Star Wars" o foco dos governos de Reagan foi a transferência dos gastos públicos para o setor de defesa cumprindo assim, sua pauta neoliberal e belicista ao mesmo tempo.

Após 1987 e principalmente ao final da Guerra Fria, com a necessidade imediata de um novo inimigo, a tônica da política externa do governo Reagan foi: 1) o "combate" às drogas, que ficou evidenciado na campanha de Nancy Reagan e a "máxima": "keep in school and stay out of drugs"; e 2) o envolvimento de George Bush em uma primeira noção de "Estados falidos" tomados pelo terrorismo, tráfico de drogas e totalitarismo fundamentalista. As elites conseguiram fazer seu sucessor ${ }^{6}$. No próximo tópico, ver-se-á primeiramente como George Bush ascendeu e justificou sua intervenção no Iraque. Ver-se-á também como os neoconservadores voltaram ao poder com George W.Bush, em 2001, e analisar-se-á quais foram os fatores que levaram a concretização da ocupação do Iraque em 2003 e a motivação por parte do governo norte-americano para tal.

\section{PAPEL DO IRAQUE NA POLÍTICA EXTERNA NEOCONSERVADORA}

\subsection{A Guerra do Golfo}

No outono de 1988, o então vice-presidente George Bush venceu o candidato democrata Michael Dukakis com 79.2\% dos votos eleitorais (426 votos) contra

${ }^{6}$ Disponível em: http://www.reagan.utexas.edu/archives/textual/smofmain.html. Acesso em: Novembro, 2015. 
25 InterAção

apenas 111 do oponente. Bush ganhou ainda $53.4 \%$ dos votos populares, tornandose o $41^{\circ}$ presidente dos Estados Unidos, aos 65 anos, tendo já sido, além de vicepresidente, diretor da Central Intelligence Agency (CIA), congressista, embaixador e piloto da marinha7 ${ }^{7}$ Com o fim da guerra-fria, havia uma necessidade eminente de um "novo inimigo" para dar sequencia ao expansionismo dos governos neoconservadores, como afirma Pecequilo:

A ideia do inimigo tornou-se funcional para o estabelecimento da identidade nacional a partir do outro, tanto que, com o fim da bipolaridade, uma das principais dificuldades estratégicas tem sido a de se estabelecer um novo "outro" (PECEQUILO, 2012, p. 6)

No acaso de George Bush o "novo outro" estava alicerçado na noção de "Estados falidos" e o Iraque foi oportuno nesse sentido, principalmente após Saddam Hussein, liderando o Partido Baath, invadir o Kuwait no dia 2 de Agosto de 1990. O que ficou conhecido como a Primeira Guerra do Golfo ou Guerra do Kuwait mostrou ao mundo a correlação de forças que passaria a ditar o sistema internacional no pós Guerra Fria.

Sob a ótica do Partido Baath, a invasão do Kuwait era uma forma de recuperação da guerra Irã-Iraque (1980-1988). O Iraque encontrava-se altamente endividado e necessitava exportar petróleo desesperadamente. Bagdá acusava o Kuwait de estar excedendo as quotas de exportação de petróleo, fazendo o preço do mesmo cair. Além disso, Saddam conjurava também antigas disputas de fronteira entre os dois países como justificativa para a invasão. Do ponto de vista de Washington, a invasão era inadmissível. O controle de Saddam sobre o Kuwait significava o controle de imensas reservas de petróleo, contrariando os interesses

\footnotetext{
${ }^{7}$ Disponível em: http://bush41.org/. Acesso em: Dezembro 2015.
} 
26 InterAção

norte-americanos e os da monarquia da Arábia Saudita, aliada preferencial de Washington na região.

As tensões entre Iraque e Estados Unidos escalonaram até que no dia 29 de novembro de 1990, Washington conseguiu que o Conselho de Segurança das Nações Unidas (CSNU) aprovasse a resolução n ${ }^{\circ} 678$ que apelava para que o Iraque deixasse o Kuwait até 15 de Janeiro de 1991, autorizando, ao mesmo tempo o recurso a “todos os meios necessários" caso a data limite não fosse respeitada. Dessa forma, não atendida a resolução por parte de Bagdá, a coalizão liderada pelos Estados Unidos atacou o palácio presidencial, a sede do Partido Baath e o Ministério da Defesa (BRITO, 2014). Revelou-se assim a tentativa de desmantelamento da estrutura do regime de Saddam Hussein.

Figura 2: Ataque ao Kuwait pelas forças de coalizão

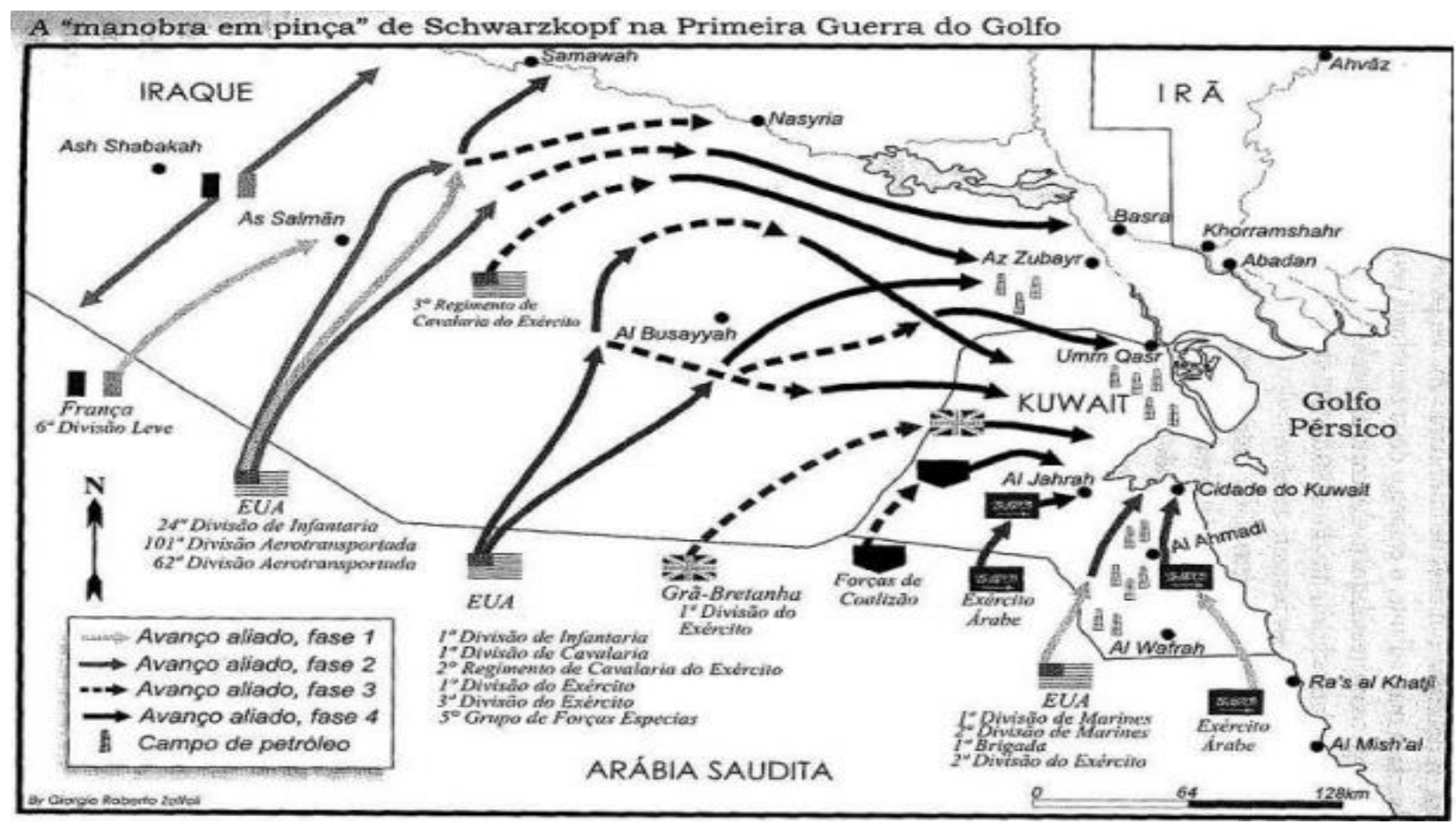

Fonte: MAGNOLI, Demétrio, org. História das Guerras. 
$27 \mid$ InterAção

Antes de iniciar sua campanha terrestre, o governo norte-americano deu um ultimato a Saddam, alegando que a coalizão daria ao Iraque até o dia 23 de fevereiro para sua retirada imediata e incondicional do Kuwait. No dia 24 de fevereiro de 1991 ocorreu enfim o ataque terrestre, que durou apenas 100 horas, deixando 150 mil baixas por parte do exército iraquiano. O general norte-americano Schwarzkopf liderou uma "manobra de pinça" (Figura 2) onde se destacaram fatores como o extraordinário poder aéreo e a integração entre todas as forças devido ao avanço da tecnologia da informação, permitindo que informações chegassem em tempo real aos comandantes (BRITO, 2014).

Após "solucionar" a questão do Kuwait, os aliados, incluindo os Estados Unidos, optaram por não avançar até Bagdá para não provocar a queda do regime do Partido Baath. Os aliados acreditaram que a queda de Saddam acarretaria em caos político e social. Nesse sentido, a atuação de George Bush foi diferente daquela de George W. Bush e seu governo. Os neoconservadores sob o comando de Bush construíram seu projeto ao longo da década de 1990- de governo democrata.

\subsection{Hiato dos anos 1990}

Após o governo George Bush "resolver" a questão do Kuwait, o cessar-fogo foi confirmado pela resolução n ${ }^{\circ} 687$ do CSNU. Esta resolução impôs uma vasta gama de condições ao regime de Saddam, como: a destruição de todas as armas químicas e biológicas que o Iraque possuísse; o compromisso de não desenvolver ou adquirir armas nucleares ou material que pudesse ser empregado na fabricação das mesmas; a destruição de todos os mísseis que tivessem um alcance de mais de 150 
28 InterAção

km; a submissão das importações à aprovação por um Comitê de Sansões; o pagamento da dívida externa e de reparações de guerra; a cooperação plena com as inspeções a serem executadas pela Comissão Especial das Nações Unidas (UNSCOM) em relação às armas químicas e biológicas, e pela Agência Internacional de Energia Atômica (AIEA) em relação às armas nucleares (BRITO, 2014). Essa seria a tônica da política externa norte-americana para o Iraque na década de 1990. O Partido Baath foi mantido no poder para a "estabilização" do país, mas não possuía poder de fato.

O governo de Clinton foi eleito com fortes críticas aos impactos sociais das políticas de Reagan e Bush. A estratégia do governo iria nortear-se pela defesa do regime democrático e do livre-mercado e no enfraquecimento dos Estados nacionais ao redor do mundo. Sob o comando de Clinton, os Estados Unidos privilegiaram os fóruns multilaterais e a defesa do regime democrático em uma década em que a posição dos Estados Unidos como única superpotência global foi inconteste. Como bem afirmou Samuel Huntington “os Estados Unidos são o único Estado com preeminência em todos os domínios- econômico, militar, diplomático, ideológico, tecnológico e cultural" (Huntington, 1999, p.23). Houve uma forte reação por parte dos neoconservadores, já que tal estratégia não contemplava a base política dos mesmos.

\subsection{George W. Bush e o retorno dos neoconservadores}

Os principais quadros que iriam compor o governo George W. Bush já se organizavam no governo Clinton. Nomes como Donald Rumsfeld e Paul Wolfovitz 
propuseram o Defense Planning Guidance (DPG) (PECEQUILO, 2012), já em 1992. Tal documento defendeu a necessidade de implementar uma atuação unilateral para desmantelar potências regionais e assumir o reposicionamento estratégico na Eurásia, vácuo geopolítico deixado com o fim da União Soviética. Grupos religiosos e lobbies do setor energético e do complexo industrial-militar, os "neocons" abriram processo de impeachment contra Clinton por ocasião de um "ato de imoralidade" por parte do presidente e lançaram o Project for the New American Century (PNAC ${ }^{8}$ ). O PNAC representava a retomada da agenda do DPG, a defesa da supremacia militar e foco na expansão na Eurásia, somados a elementos religiosos. Esses documentos compunham a agenda internacional de George W. Bush.

O PNAC nasceu na primavera de 1997 com o objetivo de ser um grupo de pesquisa que divulgaria recomendações para o governo dos Estados Unidos, principalmente nas áreas de segurança e política exterior. Entre seus quadros encontravam-se importantes membros do futuro governo de W. Bush. Documentos lançados pelo PNAC alegavam que o século XX havia ensinado que é necessário atuar no sentido de prevenir crises para preservar os interesses e os princípios dos Estados Unidos. O PNAC é riquíssimo em recomendações militares, dentre as quais, destacam-se a indicação do Iraque e do Irã como inimigos dos interesses norteamericanos, sendo o Golfo Pérsico região fundamental para a preservação dos mesmos. O grupo político que compôs o PNAC possui fortes vínculos com os lobbies do setor energético e do complexo-industrial-militar norte-americano. Dentre as políticas propostas pelo PNAC, o aumento nos gastos militares está entre os mais relevantes. Nos governos do presidente Clinton os gastos militares haviam pdf. Acesso em: Dezembro, 2015. 
30 InterAção

diminuído sensivelmente, o que para os neoconservadores era inaceitável, já que para estes a Pax Americana estava sob constante ameaça.

Com uma eleição questionável do ponto de vista democrático, George W. Bush assumiu a presidência dos Estados Unidos em janeiro de 2001. O unilateralismo logo tomou forma com a não adesão por parte dos Estados Unidos ao Tratado de Quioto e ao Tribunal Penal Internacional. Nomes como Donald Rumsfeld no Departamento de Defesa, o Vice-Presidente Dick Cheney, Paul Wolfowitz como subsecretário da Defesa, indicariam essa tendência ao unilateralismo. Uma aliança tácita também se deu por parte do governo com os grupos religiosos, realocando recursos para ensinos bíblicos e campanhas de abstinência sexual. Depois dos atentados de 11 de setembro as forças conservadoras ganharam respaldo e aceitação, o que favoreceu a construção de um novo inimigo, o terrorismo fundamentalista islâmico. Em 2002 os republicanos passaram a controlar tanto a Câmara quanto o Senado. O Patriot Act de 2001 permitiu a prisão de suspeitos, espionagem de cidadãos e encarceramento sem direito a advogado. Foi criado o Departamento de Segurança Doméstica (Homeland Security) e o USNORTHCOM (Comando do Norte, em 2001), com o propósito de combater o terrorismo internamento. Externamente a "Global War on Terrorism" ${ }^{9}$ " significou a invasão do Afeganistão em 2001 (guerra que continua em andamento) e a guerra do Iraque (2003/2011), além da recente guerra ao Estado Islâmico.

Em 2002 o pensamento neoconservador e unilateral do governo Bush tomou forma na National Security Strategy, um documento síntese do DPG e do PNAC, que reforçava a ideia de "Eixo do Mal" concebida por Bush na qual Iraque, Irã,

9 Para uma boa compreensão da chamada Guerra ao Terror recomenda-se a leitura da obra "Do 11 de setembro de 2001 à guerra ao terror: reflexões sobre o terrorismo no século XXI / organizadores: André de Mello e Souza, Reginaldo Mattar Nasser, Rodrigo Fracalossi de Moraes. - Brasília : Ipea, 2014 
31 InterAção

Coreia do Norte, Cuba, Líbia e Síria constituíam ameaças à democracia e à paz

global. É notório observar a interferência norte-americana em todos esses Estados, com intervenções militares diretas no caso de alguns, e apoio militar a insurgentes e embargos econômicos no caso dos outros. Os últimos anos do mandato de Bush foram marcados pela crise do subprime que colocou o país em um cenário de estagnação. A liberalização desenfreada do mercado de títulos e derivativos, do chamado FIRE (finanças, seguros e imobiliário) deu origem a uma crise não esperada pelos modelos neoliberais. O neoliberalismo foi acompanhado ironicamente de um keynesianismo militar, muito próximo ao modelo de Ronald Reagan.

\subsection{A ocupação do Iraque}

A postura das potências ocidentais no período entre as duas guerras do golfo (1991-2002) resumiu-se a retaliações econômicas e embargo às exportações, além de bombardeios constantes por parte das potências ocidentais e regulares inspeções feitas pela UNSCOM e a AIEA, como parte do acordo previsto na resolução nº 687 do CSNU. As inspeções acerca das armas de destruição em massa seriam peça fundamental na articulação dos Estados Unidos para arrumar um pretexto para a invasão em 2002. As agências das Nações Unidas, após anos de inspeções, concluíram categoricamente que o Iraque não possuía armas de destruição em massa.

De toda forma, para o governo de George W. Bush e seu principal aliado, a Inglaterra, no entanto, as alegações dos instrumentos da ONU não representariam a verdade e a invasão era uma questão de tempo, mesmo que para isso as potências 
32 InterAção

anglo-saxônicas tivessem que manipular organizações internacionais independentes como a Organização para Proibição das Armas Químicas (BRITO, 2014). A invasão por terra finalmente deu-se em março de 2003. A operação com apoio de uma coalizão nomeada Coalition of the Willing, contou com cerca de 150 mil soldados.

O avanço em direção à Bagdá ocorreu em menos de 20 dias, com pouca resistência por parte do exército iraquiano, mas sem o apoio esperado dos xiitas, devido ao fato de que na sublevação xiita, 12 anos antes, os Estados Unidos negaram apoio (BRITO, 2014). A derrubada do regime e a conquista do território foram relativamente fáceis. Uma ofensiva em duas colunas completou a missão. Agora a verdadeira dificuldade para a consolidação dos interesses dos aliados era a estabilização do país, sem o partido Baath.

A ocupação foi um verdadeiro desastre para o Iraque já que agravou ainda mais a situação instável do país em termos étnicos e econômicos. A composição étnica do Iraque havia sido mantida "sob controle" com o Partido Baath através de uma repressão sistemática dos Curdos e da maioria xiita. Além disso, calcula-se que mais de 200 mil iraquianos tenham morrido nos anos de ocupação (BRITO, 2014). Sob o ponto de vista econômico o Iraque tornou-se ainda mais dependente das exportações de petróleo, já que os aliados continuaram a desmantelar a infraestrutura industrial e logística do país.

O Iraque não representava de fato uma ameaça terrorista, nem sequer o regime possuía armas que poderiam ser consideradas nocivas à paz no Ocidente. Quais seriam os verdadeiros motivos da invasão? A invasão visava, sim, a mudança de regime, pois a possibilidade de uma potência regional é sempre nociva aos interesses dos Estados Unidos. Os EUA invadiram o Iraque para promover seus 
33 InterAção

interesses econômicos e geopolíticos, principalmente a segurança nos suprimentos de petróleo, o posicionamento estratégico do Iraque ao norte da Arábia Saudita, ao oeste do Irã e ao leste da Síria. Os Estados Unidos visavam à mudança de regime tanto no Iraque, como no Irã e na Síria. Dessa forma, com uma influência direta no Iraque, e no já ocupado Afeganistão, poderiam garantir seus interesses em todo o Oriente Médio, assegurando também os interesses de seu Estado pivot na região, Israel. Uma constelação de bases militares no Iraque proporcionaria aos Estados Unidos uma situação de conquista direta, o que não pode ser definido de outra forma, senão de “Novo Imperialismo"10" (HARVEY, 2004). Além disso, a invasão permitiu aos Estados Unidos o fortalecimento de um núcleo de poder interno, contemplando o interesse do complexo industrial-militar e das empresas de construção civil e infraestrutura, responsáveis pela reconstrução do Iraque após a invasão.

\section{CONSIDERAÇÕES FINAIS: REINTERPRETANDO A GUERRA DO IRAQUE E SUAS CONSEQUÊNCIAS}

Alguns anos após a retirada oficial das tropas norte-americanas do Iraque é possível interpretar o conflito de cerca de uma década a partir do pensamento neoconservador. Os ataques de 11/09 conferiram um estofo político e ideológico para que o establishment da Casa Branca e do Pentágono interviesse no Oriente Médio sob justificativas realistas e idealistas. A matriz idealista da política externa dos EUA, derivada do tipo ideal dos puritanos, pautou-se pela ideia de “Guerra

\footnotetext{
${ }^{10}$ Harvey afirma que "toda a guerra norte-americana ao terror é um exercício de imperialismo. Isso talvez choque os norteamericanos, que não gostam de conceber seu país como um império. Mas que outro nome podemos dar às legiões norteamericanas de soldados, de agentes secretos e de forças especiais espalhadas pelo globo?" (HARVEY, 2004, p. 13).
} 
$34 \mid$ InterAção

Justa", em que o excepcionalismo da experiência histórica de construção da democracia norte-americana poderia servir de modelo e inspiração para que os povos árabes, e não apenas os iraquianos, se sublevassem contra as supostas tiranias nacionais e lutassem por direitos de cidadania como a eleição de seus representantes políticos. E este fenômeno seria a base de um mundo mais pacífico porque composto por democracias que, em tese, não entrariam em guerra entre si. Não por acaso, nos primeiros momentos do que convencionou-se chamar de "Primavera Árabe", muitos analistas viam com otimismo uma sublevação de sociedades contra autoritarismos e a favor de supostos direitos e liberdades individuais.

A matriz realista da política externa dos EUA também esteve presente no pensamento e na atuação dos neoconservadores nos anos 2000. Tendo em vista a supremacia militar global norte-americana e a emergência de novos desafios geopolíticos na Eurásia (notadamente Rússia e China), este grupo vislumbrou a possibilidade de moldar o Oriente Médio a partir de seus próprios interesses de segurança, não apenas a partir do excepcionalismo dos EUA, mas também como objetivos pragmáticos e realistas típicos de qualquer grande potência.

O pouco distanciamento temporal de nosso objeto de pesquisa impossibilita quaisquer análises de longo prazo sobre seus efeitos, mas os custos da guerra cobraram seu preço em algumas áreas específicas, que merecem nossa atenção. No âmbito geopolítico, o principal ônus da mudança de regime no Iraque foi a instalação de um governo xiita fraco, sem legitimidade e que, precisamente por sua incapacidade de chegar às regiões de maioria sunita e curda, propiciou a penetração de redes e grupos paramilitares como a Al-Qaeda e o Estado Islâmico. Muitos dos chefes militares de Saddam Hussein, removidos de suas posições no processo de desbaathização executado pelos EUA, encontraram abrigo nesses grupos 
35 InterAção

paramilitares que, por alguns anos, receberam auxílio financeiro dos próprios norteamericanos desesperados para dar um basta na onda de atentados à bomba no Iraque em meados dos anos 2000.

Os custos econômicos também não são desprezíveis. Em 2009, logo após a eleição de Barack Obama, a dívida pública dos EUA atingira 100\% do PIB e embora o país tivesse a prerrogativa, única no mundo, de imprimir sua própria moeda sem precisar lastreá-la em outra, os danos em diversos setores da economia foram sentidos. Com a redução da taxa de juros a quase zero, o governo não apenas endividou-se com bancos centrais estrangeiros, mas estimulou a expansão do crédito das famílias que culminou na crise imobiliária do subprime em 2007 e 2008. As empresas norte-americanas também tiveram um achatamento de suas taxas de lucro e a elevação dos custos de produção e perda da competitividade das firmas nos EUA acentuou o processo de transferência de parte das cadeias produtivas para a Ásia e outras partes do mundo.

Por fim, a Guerra do Iraque trouxe custos simbólicos para o argumento da liderança moral dos EUA. No plano doméstico, a criação do Ministério de segurança Interior (Department of Homeland Security) e a criação de leis como o Ato Patriota (Patriot Act) colocaram em xeque a democracia e os valores de liberdade individual e livre expressão de ideias, tão caros à sociedade norte-americana. No plano externo, a invasão do Iraque à revelia das determinações do Conselho de Segurança da ONU significou um desprezo a instituições e normas internacionais no momento em que elas obstam a vontade unilateral do governo dos EUA.

Por fim, talvez o ônus transversal da Guerra do Iraque, que perpassa custos geopolíticos, econômicos e ideológicos, tenha sido o lançamento do Oriente Médio em uma nova rodada de instabilidade, acentuada pelo esfacelamento de dois 
36 InterAção

Estados, Iraque e Síria, e pelo vácuo de poder ocupado por grupos como o Estado Islâmico nos anos mais recentes.

\section{REFERÊNCIAS}

BRITO, Bernardo de Azevedo. Iraque: dos primórdios a procura de um destino. Florianópolis: Ed da UFSC, 2014

FIORI, José Luís; O sistema interestatal capitalista no início do século XXI. In ; MEDEIROS, Carlos A; SERRANO, Franklin P. O mito do colapso do poder americano. Rio de Janeiro: Record, 2008.

HARVEY, David. O Novo Imperialismo. Editora Loyola: São Paulo, 2004.

HENDLER, Bruno. Ônus e bônus da Guerra ao Terror: custos para os EUA e ganhos relativos da China em tempos de mudança no sistema-mundo moderno. Curitiba: Instituto Memória, 2015.

KARNAL, Leandro. História dos Estados Unidos: das origens ao século XXI. São Paulo: Editora Contexto, 2007.

LIBRARY \& MUSEUM, Ronald Reagan Presidential. Ronald Reagan's Major Speeches, 1964-89. Disponível em: http://www.reaganlibrary.gov/majorspeeches-index. Acesso em: Novembro, 2015.

LIBRARY \& MUSEUM. Ronald Reagan Presidential. White House Staff and Office Files. Disponível em:

http://www.reagan.utexas.edu/archives/textual/smofmain.html. Acesso em: Novembro, 2015.

LIBRARY \& MUSEUM, George Bush Presidential. Disponível em: http://bush41.org/. Acesso em: Novembro, 2015.

SOUZA, André de Mello, NASSER, Reginaldo Mattar, FRACALOSSI, Rodrigo de Moraes (orgs). Do 11 de setembro de 2001 à guerra ao terror: reflexões sobre o terrorismo no século XXI. Brasília : Ipea, 2014 
37 InterAção

PECEQUILO, Cristina Soreanu. Os Estados Unidos e o Século XXI. Rio de Janeiro, 2012.

PNAC. Rebuilding America's Defenses: Strategy, Forces and Resources For a New Century. Disponível em:

https://web.archive.org/web/20130817122719/http://www.newamericancentur y.org/RebuildingAmericasDefenses.pdf. Acesso em: Dezembro, 2015. 